\title{
Çocukluk Çağında Mikroskopik Kolite Yaklaşım
}

\section{Çocukluk Çă̆ında Mikroskopik Kolite Yaklaşım}

\section{Nafiye Urganc1}

Şişli Hamidiye Etfal Çocuk Sağlığı ve Hastalıklar Pediatrik Gastroenteroloji

\section{$\ddot{O} Z$}

Mikroskopik Kolit; kronik sulu ishal, normal endoskopik ve histopatolojik bulgular ile karakterize inflamatuvar değişiklikler gösteren nadir bir barsak hastalığıdır. Kronik diarenin sık görülen bir nedenidir. Kollajenöz kolit ve lenfositik kolit (LK) olmak üzere iki subtipi mevcuttur. Klinik ve histopatoloik özellikleri benzer olan bu tiplerinin biribirinden ayrı hastalık mı,yoksa aynı hastalığın farklı fenotipleri mi olduğu halen bilinmemektedir. Etyolojisi bilinmemekle birlikte; genetik, otoimmunite, luminal bir antijene karşı (gıda, mikroorgaanizma vs) immunolojik veya inflamatuvar reaksiyon, ilaçlar, bakteriyal infeksiyon ve toksinleri, safra asitleri ve safra asit malabsorbsiyon, bozulmuş sıvı ve elektrolit emilimi ve salınımı, kollajen sentez-degredasyon (parçalanma) dengesi ve nitrik oksit öne sürülen başlıca mekanizmalardır. Erişkin yaş grubunda sıklıkla altıncı ve yedinci dekatlarda daha fazla olmakla birlikte çocuk yaş grubu dahil her yaş grubunda giderek arttığ bildirilmektedir. Çocukluk çağında MK'in sıklığı bilinmemektedir. Klinik bulguları nonspesifik olup ikisinde de kronik veya tekrarlayan sulu, kansız, dehidratasyona neden olmayan şiddetli, gecede olabilen ishal, karın ağrısı, kramplar, kilo kaybı ve fekal inkontinans görülür. Rutin laboratuvar incelemeler genellikle yardımcı değildir Tanı çoğu zaman klinik belirtiler varlığında, alınan biyopsilerle histolojik olarak konulabilmektedir. Bu amaçla çıkan ve sigmoid kolondan biyopsi alınmalıdır. Ayırıcı tanıda, ilaca bağlı mikrosopik kolit ve çölyak hastalığı mutlaka ekarte edilmelidir. Tedavisinde fazla kontrollü çalışma yoktur. En fazla çalışılan ilaç budesoniddir. Hafif vakalarda anti-diareikler genellikle yeterli olmaktadır. Genel olarak MKin uzun süreli izlem sonucunda prognoz oldukça iyidir.

Anahtar Kelimeler: Mikroskopik kolit, Kollajenöz kolit, lenfositik kolit, çocukluk çağ1 


\section{SUMMARY}

Microscopic colitis (MC), is a rare disorder characterised by chronic watery diarrhea, normal endoscopic and histopathological findings and inflammatory changes. MC is one of the most frequent causes of chronic diarrhea. MC is divided into two subgroups; collagenous colitis and lymphocytic colitis. It is still unclear, if these subgroups are the same disease with similar clinical and histopathological characteristics or they are different phenotypes of the same disease. Although etiology is unknown, proposed mechanisms of MC are genetics, autoimmunity, immunological or inflammatory reactions to a luminal antigen (food, microorganisms vs), drugs, bacterial infections and toxins, malabsorption of bile acids and bile, defective absorption of fluid and electrolytes, equilibrium of collagen synthesis and degradation and nitric oxide. The prevalence is higher among adults, especially 6th and 7th decades of life, but increasing in every age group including childhood. MC has nonspecific signs such as chronic, recurrent, watery, nonbloody diarrhea which does not cause dehydratation, abdominal pain, weight loss, fecal incontinence. The laboratory examinations are usually not helpful. The diagnosis is made on the basis of clinical signs and histopathological examinations of biopsy specimens taken from ascendent colon and sigmoid colon. Microscopic colitis caused by drugs and celiac disease should be excluded in the differential diagnosis of the disease. There are not enough well-controlled studies about the treatment of MC. Budesonid is the most studied drug. Anti-diarrheals are usually efficient in mild forms of MC. The long-term prognosis is fairly well.

Keywords: Microscopic colitis, collagenous colitis, lymphocytic colitis, childhood 


\section{Giriş}

Mikroskopik kolit (MK), son y1llarda kansız, kronik sulu ishal, normal endoskopik veya radyolojik bulguların yanı sıra histopatolojik olarak kronik mukozal inflamasyon ile karakterize oldukça nadir inflamatuvar barsak hastalığı olarak tanımlanmaktadr.(1,2). Mikroskopik kolit terimi, ilk kez 1980'de sebebi bilinmeyen kronik ishali olan hastaların bir grubunda tanımlanmıştır (3). Spesifik (Kollejenöz kolit (KK), Lenfositik kolit (LK), Hafif idiyopatik inflamatuvar barsak hastalı̆̆ı, (Crohn ve Ülseratif kolit gibi), Eozinofilik (allerjik) kolit, Kronik iskemik kolit, Enfeksiyöz kolit, Nonsteroidal antiinflammatuvar (NSAİ) ilaç ilişkili kolitler gibi pekçok hastalığın tanımında da kullanılmıştır (4,5).Bununla birlikte günümüzde Mikroskopik kolit terimi, kollajenöz kolit ve lenfositik kolit (LK) subtiplerini içermektedir (6,7). Kollajenöz kolit (KK) terimi ilk kez 1976'da kolonik mukozada subepiteliyal kollajen band1 >10 mikron, lamina propriada minimal kronik inflamatuvar hücre infiltrasyonu ve sulu ishali olan hastalarda tanımlanmıştır (8). Lenfositik Kolit ise 1989 yılında Lazenby ve ark'ları tarafından mikroskopik bulguları kollojenöz kolite benzeyen, kolonda kollajen bandında kalınlaşma olmayan ve normal kript yapısına karşın intraepitelyal lenfosit ( > 20 intraepitelyal lenfosit /100 kolon hücresi) artışı olan olgularda tanımlanmıştır $(9,10)$. Bu iki durum benzer gastrointestinal semptomlara ve histopatolojik anormalliklere sahip olsalar da, kendi aralarında klinik ve histolojik farklılıklara sahip olduklarından farklı hastalıklar mı yoksa aynı hastalığın farklı evreler mi olduğu tartışılmaktadır.

\section{Epidemiyoloji:}

Kronik ishalli erişkinlerde MK sıklığının \%4-13 olduğu, son yıllarda \%20 lere çıktığı bildirilmektedir ( 11,12). Avrupa ve kuzey Amerika'da KK ‘ nın insidans1 0.6-5.2/100 000 . LK 'nın insidans1 3.7-5.5/ 100000 olarak bildirilmiştir $(2,12,13)$. Ülkemizde kronik ishalli erişkinlerde yapılan çalışmada MK sıklığı \%10, bunun \%9'nun LK, \%2.5'nin KK olduğu saptanmıştır (14). Mikroskopik kolit sıklığı erişkin yaş grubunda sıklıkla altıncı ve yedinci dekatlarda daha fazla olmakla birlikte çocuk yaş grubu dahil her yaşta görülmektedir (9,14-17). Çocukluk çağında MK'in sıklığı bilinmemekle birlikte literatürde değişik yaşlarda olgu bildirimleri ve hatta (18-27). en küçük 2 yaşında bir olguda bildirilmiştir (28). Kollajenöz kolit kadınlarda (kadın/ erkek oranı 2.4/1 ile 6/1) daha fazla görülmekle birlikte lenfositik kolitte cinsiyet farkının olmadığı bildirilmektedir $(1,2,11,15)$.

\section{Etiyopatogenez:}

Mikroskopik kolitin esas sebebi bilinmemektedir. Multifaktöryel olduğu ileri sürülmektedir. Günümüzde kişisel yatkınlığı olanlarda çeşitli mukozal hasara karşı anormal immunolojik reaksiyon sorumlu tutulmakla birlikte; genetik, otoimmunite, luminal bir antijene karşı (gıda, mikroorgaanizma vs) immunolojik veya inflamatuvar reaksiyon, ilaçlar, bakteriyal infeksiyon ve toksinleri, safra asitleri ve safra asit malabsorbsiyon, bozulmuş sıvı ve elektrolit emilimi ve salınımı, kollajen sentezdegredasyon (parçalanma) dengesi ve nitrik oksit öne sürülen başlıca mekanizmalardır $(15,29,32)$. 
1-Genetik: Mikroskopik kolitin genetik olup olmadığı bilinmemekle birlikte az sayıda literatürde ailesel olduğu bildirilmek ancak bunların genetik mi yoksa raslantısal birliktelik mi olduğu net açıklanamamaktadır (12,17,29). Mikroskopik kolitinin HLA_DQ2 ve DQ1-3 ile ilişkili olduğu gösterilmiş iken son y1llarda kontrol grubuna göre daha fazla oranda HLA-DR3 -DQ2 haplotipi ile TNF 2 allel taşıyıcısı arasında bağlantı olduğu ancak bunun çöliak hastalığı ile ilişkili olmadığı gösterilmiştir $(31,32)$. Kollajenöz kolit ile matriksmetaloproteaz (MMP)9 gen çeşitleri arasında da bir ilişki olabileceği bildirilmektedir (33). Ancak NOD2/CARD15 polimorfizmi ile ilişki bulunamamıştır (34).

2-Otoimmunite: Mikroskopik kolitli olguların yaklaşık \%30-50 sinde otoimmun hastalıklar (Çöliak hastalı̆̆1, tiroidit, Tip-1 Diabetes mellitus, romatoid artirid, psöriazis, sögren's sendrom, fibromiyalji, CREST sendromu) ve immun yetersizlik birlikte görülmektedir $(1,12,15,16,17,24)$. Çocuk ve erişkinlerde LK ile Çöliak hastalı̆̆ birlikteliği \%2-15, Diabetes Mellitus ile \%8.3-13.5 olarak belirtilmiştir (15). Kollajenöz kolitli çocuk olguların çok azında crohn hastalığı, eozionofilik gastroenterit, otizm ve juvenil skleroderma birlikteliği gösterilmiştir $(19,35,36)$

Mikroskopik kolit ile ilgili otoimmun belirteç bulunmamakla birlikte antinükleer antikor, perinükleer antinötrofil sitoplazmik antikor, antigliadin antikor pozitifliği ve İmmungloblin M düzeyinde artış saptanabilir Tedaviye yanıtsı MK olgularında çöliak hastalığı başta olmak üzere diğer otoimmun hastalıklar düşünülmelidir $(1,12,16,17)$.

3-Luminal faktörler: Besinsel antijenler, ilaçlar, safra tuzları ve bakteriyal ürünler ve toksinlerin duyarlı kişilerde mukozal inflamasyona, intraluminal cevap olarak da intraepitelyal T lenfosit sayısında artışa yolaçtığı gösterilmiştir Bu teori fekal akımın diversiyonu sonrası klinik ve histopatolojik düzelme ile desteklenmiştir. İleostomi kapandıktan sonra klinik ve histopatolojik bulguların tekrarlaması fekal içeriğin sitotoksik olduğunu düşündürmektedir $(1,29)$.

4-İlaçlar: İlaçlar ve onları metabolitleri ya doğrudan farmakolojik etkileri yada idiyosenkrazik aşırı duyarlık reaksiyonu ile veya da kolon florasını değiştirerek dolaylı olarak kolon mukozasında hasara neden olurlar (19). Pek çok ilaç MK'in patogezinden sorumludur. Aspirin başta olmak üzere NSAİ'ler, proton pompa inhibitörleri (PPI)( lansaprazol,omeprazol, esomeprazol), ranitidin, selektif seratonin tekrar alım inhibitörleri (SSRI), ticlopidin, carbazapemin, acorbose, statinler, cyclo 3 fort, setralin, flutamid, lisinopril, madopar, oxetorone, paroxetin, simvastadin ve tardiferon Lenfositik kolite neden olurken, NSAI'lar, lansaprazol ve simetidin ise kollajenöz kolite yol açmaktadır (1,2,12,15-17,29). Literatürde uzun süre NSAİ kullanımı sonrası kolonik mukozal permeabilite artma ve lamina propria’ya giren lüminal antijnenlerin inflamasyonu başlatması sonrası \%34-71 oranında kollajenöz kolit oluştuğu ve ilacın sonlandırılması ile klinik ve histolojik iyileşmenin gözlendiği ileri sürülmektedir. Buna karşın ilacın kullanımı ile KK ve LK arasında ilişikinin olmadığı da bildirilmektedir $(1,2,16,17)$.

5-Bakteriyal infeksiyon ve toksinleri: Ani başlayan karın ağrısı, ishal olgularında infeksiyöz nedenler düşülmelidir. Camfilobakter jejuni, Clostridium difficile ve Yersinia enterocolitica infeksiyonunun MK 
ile ilşikili olduğu bildirilmektedir. Olguların büyük çoğunluğunda kültürde üreme olmamaktadır $(1,2,29)$.

6-Safra asitleri ve safra asit malabsorbsiyon: Safra saitleri MK'in patogenezinde endojen luminal faktör olarak rol oynar. MK 'de oluşan ileal villus atrofisi, inflamasyon, ve kollajen depolanması safra asit malabsorsiyonunun (SAM) olası mekaniizmalarıdır. Kollajnöz kolitli olguların \%27-44' ünde , LK'li olguların ise \%9-60 inda SAM görülmektedir. Mikroskopik kolitli olgularda safra asit malabsorsiyonun olması olgularda ishalin daha da ağır seyretmesine yolaçmaktadır. Safra asit emilim bozukluğunun gösterilmesi safra asit bağlayıcı reçinelerin tedavide kullanılmasına neden olmuştur $(1,17)$.

7-Bozulmuş sıv ve elektrolit emilimi ve salınımı: Mikroskopik kolitte ishal sekretuvar veya osmotiktir. İshalin mekanizması tam olarak açıklanamaktadır. Kollajenöz kolitte ishal, epitel hücre hasarı, lamina propriadaki inflamasyon ve emilime engel olan kollajen tabakanın kalınlaşması sonucu $\mathrm{Na}$ ve $\mathrm{Cl}$ emiliminin azalması ve artmış $\mathrm{Cl}$ sekresyonundan dolayı oluşmaktadır. Ayrıca, occludin ve claudin-4 gibi sıkı bağlantı moleküllerinin bozulması da sekretuvar ishale neden olmaktadır $(37,38)$. İshalin ciddiyetinin kollajen bandın kalınlığı ile değil lamina propriadaki inflamasyonun yoğunluğu ile ilişkili olduğu ve ishal oluşumunda inflamasyonun daha etkili olduğu gösterilmektedir. Klinik gözlemlerde açlıkta osmotik ishalin azaldığı da gösterilmiştir (37).

8-Kollajen sentez- degredasyon dengesi: Normal kolonik histolojide kolonda subepitelyal alanda tip IV kollojen bulunmaktadır. Kollajenöz kolitte ise bu kollajen tabaka tip III ve fibronektin karışmından oluşurken, subepitelyal kollajen bandının sadece tip IV kollajen içerebileceği de gösterilmiştir . Kollajenöz kolitteki aşırı kollogen birikmesinin sebebi belli olmamakla birlikte perikriptal fibroblast kılıfinda üretilen kollojenin yapımı, yapısı, yıkımı ve epitel ile lamina propria arasındaki yüzeyde lokalize olan subepiteltal mıyelofibroblast artışı sorumlu olmaktadır (39).

9-Nitrik oksit (NO): Mikrokopik kolit'te NO rolü belli değildir. Uyarılabilir nitrik oksit sentetazın kolon epitelinde aşırı artmasının KK ishal patofizyolojisinde rol oynadığı ve budenozid tedavisi ile İNOS mRNA düzeyinde belirgin azalma ile birlikte klinik ve histopatolojik iyileşme olduğu belirtilmektedir (40)

\section{Klinik Bulgular:}

Kollajenöz Kolit ve LK klinik bulguları nonspesifik olup benzerdir. Her ikisinde de kronik veya tekrarlayan sulu, kansız, dehidratasyona neden olmayan şiddetli, gecede olabilen ishal, karın ağrısı, kramplar, kilo kaybı ve fekal inkontinans görülür. İshal sayısı 8 kez/gün iken bazı olgularda 30 kez/gün olabilir. İshal aralıklı veya tipik olarak haftalar ve aylarca süren devamlı bir ishal şeklinde olabilir. Hayat kalitesi ishalin miktarı ve fekal inkontinas nedeni ile etkilenmiştir (12,15, 23-26,35). Ani başlangıçlı ishaller infeksiyöz ishalleri taklit edebilir (11). Klinik seyir sıklıkla kronik, tekrarlayıcı ve selimdir. Bazı hafif yakınması olan olgular irritabl barsak sendrom ile karışabilir (41). Ciddi komplikasyon nadirdir ancak spontan veya kolonoskopi sırasında perforasyon bildirilmiştir (42). Kolorektal kanser riski yoktur. Ancak sigara içen kadınlarda akciğer ve lenfoma riski olabillir (12) 


\section{Laboratuvar:}

Mikroskopik kolitte kan ve gaita incelemeleri sıkl1kla normal ve nonspesifiktir. Sedimantasyonda, CRP'de hafif artma, hafif anemi, eozinofili, vitamin B 12 seviyesinde düşüklük ve hipoalbuminemi saptanabilir $(12,15,35)$. Fekal kalprotektinde hafif artış veya azalma, laktoferritin, fekal eozinofil protein X, fekal eozinofilik katyonik proteinde artma saptanabilir. Olguların \%55'ünde fekal lökosit tespit edilmiştir Bazı olgularda hafif steatore (günlük fekal yağ oranı 6-10 gr/gün arasındadır) de bulunabilir. Kollojenöz kolit'li olgularda Kromogranin A ve B ve sekretonörin'de artış,(12), Antinükleer antikor (\%50), perinükleer antinötrofilik sitoplazmik antikor (\%4), Romatoid faktör pozitif ve kompleman C3, C4' te artma saptanabilir (12,35).

\section{Görüntüleme:}

Mikroskopik Kolit’te radyolojik ve kolonoskopik inceleme genellikle normaldir. Kolonoskopide eritem, ödem ve anormal vasküler değişklik gibi minör ve non-spesifik anormallikler görülebilir. Kolonoskopide 'kedi tırmığı kolon" diye tanımlanan kolon yırtıkları gözlenmesi perforasyon riskini göstermektedir (12).

\section{Histopatolojik inceleme:}

Lenfositik Kolit'te biyopside yüzey epitel hasarı normal veya normale yakın kript yapısı ve lamina propriada kronik iltihabı hücre infiltrasyonu ile birlikte 100 epitel hücresinin 20'sinden fazlasinda lenfositler bulunmaktadır. Kollojenöz Kolitde intaepitelyal lenfosit artışı belirgin değildir. Ancak en önemli histolojik bulgu anormal olarak kalınlaşmış subepitelyal kollojen bandın 10 mikron'dan fazla (normalde >3 mikro) bulunmasıdır. Tanı için rektosigmoid biyopsi yeterli değildir. Lenfositik Kolit' te sağ kolonda lenfosit infiltrasyon daha belirgindir. Kollojenöz Kolit'de kollojen band kalınlığı düzenli değildir, her bölge aynı oranda tutulmaz, sağ ve transvers kolonda daha kalın rektosigmoid bölgede daha incedir (12).

\section{Tedavi:}

Tedaviye yönelik tek bir ilaç yoktur ve genellikle empiriktir Tedavide amaç; hastanın yaşam kalitesini ve semptomların iyileşmesini sağlamaktır. Ancak histolojik iyileşmenin olup olmadığı belli değildir. Tedaviye başlamadan önce hastalığa neden olan ilaçlar kesilmeli ve diyet verilmeli, çöliak gibi malabsopsiyon bulguları varsa malabsorpsiyona yol açan hastalıklar araştırılmalıdır. Hastalığın değişken klinik seyri, yüksek spontan remisyon ve tedavi sonrası remisyona girme özelliğinden dolayı tedavi seçimi hastalığın ciddiyetine göre seçilmelidir. Tedavide antidiyareikler, kolestiramin, budesonid, prednizolon. aminosalisilatlar, bismut Subsalisilat, antibiyotik-probiyotik- Boswellia serrata ekstrakt1 ve immunsupresif uygulanmaktadır (12,15, 23-27, 43-45).

Mikroskopik kolitte tedavi klinik ve kişisel cevaba göre Avrupa MK grubunun (http// www.emcg$\underline{\text { ibd.eu) }}$ önerdiği algoritmaya göre uygulanmaktadır (Sekil -1) (12). Etkinliği randomize plasebo kontrollü çalışmalarda kullanılmasada lopermid veya kolestiramin hafif MK de sıklıkla önerilen ilk basamak tedavisidir. $(1,15,17)$. Budesonid Prednizolona göre MK tedavisinde en güçlü kanıta sahip, 
klinik bulguların iyileşmesi ve hayat kalitesinin artmasında oldukça etkili bir kortikosteroiddir $(15,24$, 26,27, 44). Çocukluk çağın MK olgularında mesalazin ve Bismut Subsalisilat ile iyi yanıt alındığı bildirilmektedir (15,45). Metronidazol, Lactobasillus acidophilus LA-5 ve Bifidobacterium animalis subpp, lactis BB12 (AB-cap-10 ) gibi probiyotikler ile yeterli klinik yanıt sağlanamamıştır $(26,46)$. Budenosid veya diğer tedavilere yanıtsız veya steroide dirençli hastalarda azatiopurin,6-merkaptopurin kullanilabilir ancak yeterli veri yoktur $(14,24,39)$. Son yıllarda infliximab veya adalimumabın seçilmiş olgularda kullanılabileceği önerilmektedir $(48,49)$. Steroide dirençli olguların sıklığı bilinmemekle birlikte \%1.3 olduğu tahmin edilmektedir (49).

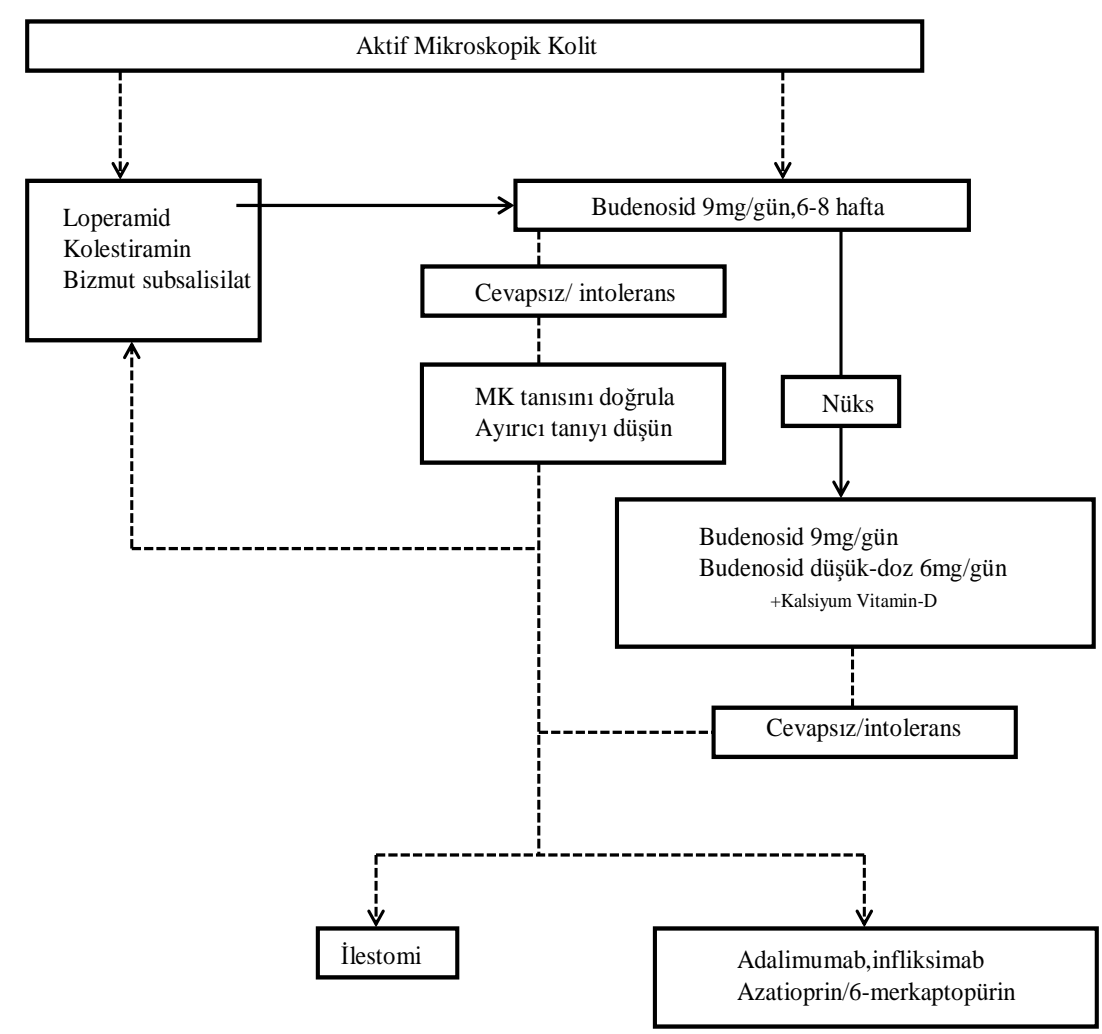

Şekil-1 Avrupa Mikroskopik Kolit grubunun önerdiği Mikroskopik tedavi yaklaşım algoritması. Bohr J et al.Clinical and Experimental Gastroenterology ,2014

Cerrahi tedavi: Medikal tedavi ile iyi sonuç elde edilemeyen veya hiç bir tedaviye cevap vermeyen ciddi olgularda düşünülmelidir. Hem diverting ileostomi, hemde subtotal kolektominin başarı ile uygulandığı bildirilmektedir (50).

\section{Prognoz:}

Genel olarak MKin uzun süreli izlem sonucunda prognoz oldukça iyidir. KK te klinik seyir; $85 \%$ aralıkl1, \%13 devamlı, \%2 tek atak şeklinde devam eder. Uzun süreli izlemde LK li olguların \%60-93, KK ' li olguların ise \%2-92 si y1llar sonra (3,5 y1l) semptomatik olarak remisyona ( günlük dışkılama sayısı $<3$ ve son bir haftada günlük $>1$ sulu dışkılama) (17) girmektedir (16). Olguların sadece 1/3'nün ilaç kullanmaya devam ettiği belirtilmektedir (37). Klinik çalışmalarda olguların \%60-80'inde idame tedavinin kesilmesinden 2-8 hafta sonra hastalığın semptomlarının tekrarladığı bildirilmektedir (56). 
Lenfositik kolitli olguların \%60'inda sadece bir atak olmakta ve ortalama 6 ay içinde semptomlar kaybolmaktadır (37).

Sonuç olarak; Mikroskopik kolit kronik diyarenin giderek artan bir nedenidir. Açıklanamayan ishal olgularında tüm olgular kolonoskopi ile değerlendirilmelidir. Mikroskopik kolitin 2 alt tipinin de klinik ve histolojik ve tedaviye verdiği yanıtlar benzerdir. Tedavi kararı verirken hastalı̆̆ın ciddiyeti, semptomların seyiri, yaşam kalitesine etkileri ve önceki tedavilere verilen cevabı göz önünde bulundurulmalıdır. Tedaviye cevapsız olgular eşlik eden hastalıklar ve kullanılan ilaçlar açısından değerlendirilmelidir. Hastalığın tanısında ve izlemde aktivitesini değerlendirecek göstergeye ihtiyaç vardır. Hafif semptomlu hastalarda antidiyarik tedavi oldukça faydalı olurken ciddi bulguları olan hastalarda budenosid ilk seçenek olmalıdır. Hastalığı tekrarlayan olgularda budenosid aralıklı ve düşük dozlarda devam edilmelidir. Budenosid cevapsız hastalarda immün supresif dışında alternatif bir tedavi yoktur. Hiç bir tedaviye yanıt vermeyen olgularda ise cerrahi tedavi düşünülmelidir.

\section{Kaynakça}

1- Pardi DS, Kelly CP. Microscopic colitis. Gastroenterology. 2011;140: 1155-65.

2- Münch A, Aust D, Bohr J, Bonderup O, Fernández Bañares F, Hjortswang H, et al. Microscopic colitis: current status, present and future challenges: statements of the European Microscopic Colitis Group. J Crohns Colitis. 2012;6:932-45.

3- Read NW, Krejs GJ, Read MG, Santa Ana CA, Morawski SG, Fordtran JS. Chronic diarrhea of unknown origin. Gastroenterology 1980; 78: 264-71.

4- Jackson BK: Are collagenous aolitis and lymphocytic colitis distinct syndromes? Dig Dis Sci 1995; 13: 301-11.

5- Zeroogian JM, Chopra S: Collagenous colitis and lymphocytic colitis. Annu Rev Med 1994; 45: 10518.

6- Jessurun J, Yardley JH, Lee EL, Vendrell DD, Schiller LR, Fordtran JS. Microscopic and collagenous colitis: different names for the same condition? Gastroenterology. 1986;91:1583-4.

7- Levison DA, Lazenby AJ, Yardley JH. Microscopic colitis cases revisited. Gastroenterology. 1993;105:1594-6.

8- Lindstrom CG: "Collagenous colitis" with watery diarrhea: a new entity? Patbol Eur 1976; 11: 87-9.

9- Fernandez-Banares F, Salas A, Esteve M, Espinos J, Forne M. Collagenous and lymphocytic colitis:

Evaluation of Clinical and Histological Features, Response to Treatment, and Long-term Follow-Up. Am J Gastroenterol. 2003; 98: 340-7 
10- Lazenby A, Yardley J, Gairdiello, Jessurun J, Bayless TM.. Lymphocytic (microscopic) colitis: a comparative histopathologic study, with particular reference to collogenous colitis. Hum Pathol 1989; 20: $19-28$.

11- Pardi DS, Loftus EV Jr, Smyrk TC, Kammer PP, Tremaine WJ. The epidemiology of microscopic colitis: a population based study in Olmsted County, Minnesota. Gut 2007;56:504-8.

12- Bohr J, Wickbom A, Hegedus A, Nyhlin N, Hultgren Hörnquist E, Tysk C. Diagnosis and management of microscopic colitis: current perspectives.Clin Exp Gastroenterol. 2014;21:273-84.

13- Gentile NM, Khanna S, Loftus EV Jr, Smyrk TC, Tremaine WJ, Harmsen WS, et al. The epidemiology of microscopic colitis in Olmsted County from 2002 to 2010: a population- based study. Clin Gastroenterol Hepatol 2014;12;:838-42.

14- Erdem L, Yildirim S, Akbayir N, Yilmaz B, Yenice N, Gultekin OS, Peker O. Prevalence of microscopic colitis in patients with diarrhea of unknown etiology in Turkey. World J Gastroenterol. 2008;21:4319-23

15- Narla NP, Smyrk TC, Pardi DS, Tung J. Clinical features and treatment responses in pediatric lymphocytic and collagenous colitis. J Pediatr Gastroenterol Nutr. 2013;57:557-61.

16- Yen EF, Pardi DS.Review article: Microscopic colitis--lymphocytic, collagenous and 'mast cell'colitis. Aliment Pharmacol Ther. 2011;34:21-32.

17- Münch A, Aust D, Bohr J, Bonderup O, Fernández Bañares F, Hjortswang H,Madisch A, Munck LK, Ström M, Tysk C, Miehlke S; European Microscopic Colitis Group (EMCG). Microscopic colitis: Current status, present and future challenges: statements of the European Microscopic Colitis Group. J Crohns Colitis. 2012;6:932-45.

18- Mahajan L, Wyllie R, Goldblum J. Lymphocytic colitis in a pediatric patient: a possible adverse reaction to carbamazepine. Am J Gastroenterol 1997;92:2126-7.

19- O'Beirne JP, Ireland A. Progression of collagenous colitis to Crohn's disease. Eur J Gastroenterol Hepatol 2005; 17:573-5.

20- Ozturk Y, Soylu OB, Ozer E. Lymphocytic colitis in a child with nonresponsive celiac disease. Acta Gastroenterol Belg 2008;71:393-5.

21- Benchimol EI, Kirsch R, Viero S, Griffiths AM.Collagenous colitis and eosinophilic gastritis in a 4-year old girl: a case report and review of the literature. Acta Paediatr 2007;96:1365-7.

22- Esselinckx W, Brenard R, Colin JF, Melange M. Juvenile scleroderma and collagenous colitis. The first case. J Rheumatol 1989;16:834-6.

23- Kuhn BR, Mezoff AG. Pediatric lymphocytic colitis presenting with intractable diarrhea. J Pediatr Gastroenterol Nutr 2011;53:579-81.

24- Liu X, Xiao SY, Plesec TP, Jiang W, Goldblum JR, Lazenby AJ. Collagenous colitis in children and adolescents: study of 7 cases and literature review. Mod Pathol 2013;26:881-7. 
25- Singh P, Das P, Jain AK, Mathan M, Mathur M, Bhat AS, Varma S, Chaturvedi MK,Gupta SD, Bhatnagar S. Microscopic colitis in children with chronic diarrhea. J Pediatr Gastroenterol Nutr. 2013;57:240-4.

26- El-Matary W, Girgis S, Huynh H, Turner J, Diederichs B. Microscopic colitis in children. Dig Dis Sci. 2010;55:1996-2001.

27- Vanderhoof JA, Goble K, Young RJ. Collagenous colitis in a 4-year-old child: response to budesonide J Pediatr Gastroenterol Nutr.2010: 50:688.

28- Najarian RM, Hait EJ, Leichtner AM, Glickman JN, Antonioli DA, Goldsmith JD. Clinical significance of colonic intraepithelial lymphocytosis in a pediatric population. Mod Pathol. 2009;22:1320.

29- Löfberg R. Microscopic and Collagenous colitis. Evidence-based gastroenterology and Child healty. Ed: john WD McDonald, Andrew K Burroughs, Brian G Feagan, second ed, 2002;pp 221-9

30- Järnerot G, Hertervig E, Grännö C, Thorhallsson E, Eriksson S, Tysk C et al. Familial occurrence of microscopic colitis: a report on five families. Scand J Gastroenterol. 2001;36:959-62.

31- Fine KD, Do K, Schulte K, Ogunji F, Guerra R, Osowski L, et al. High prevalence of celiac spruelike HLA-DQ genes and enteropathy in patients with the microscopic colitis syndrome. Am $\mathbf{J}$ Gastroenterol. 2000;95:1974-82.

32- Koskela RM, Karttunen TJ, Niemelä SE, Lehtola JK, Ilonen J, Karttunen RA. Human leucocyte antigen and TNF $\alpha$ polymorphism association in microscopic colitis. Eur J Gastroenterol Hepatol. 2008;20:276-82.

33- Madisch A, Hellmig S, Schreiber S, Bethke B, Stolte M, Miehlke S. Allelic variation of the matrix metalloproteinase-9 gene is associated with collagenous colitis. Inflamm Bowel Dis 2011;17: 2295-8. 34- Madisch A, Hellmig S, Schreiber S, Bethke B, Stolte M, Miehlke S. NOD2/CARD15 gene polymorphisms are not associated with collagenous colitis. Int J Colorectal Dis 2007;22:425-8.

35- Camarero Salces C, Enes Romero P, Redondo C, Rizo Pascual JM, Roy Ariño G. Collagenous colitis and collagenous gastritis in a 9 year old girl: a case report and review of the literature. Acta Gastroenterol Belg. 2011;74:468-74.

36- Chen B, Girgis S, El-Matary W.Childhood autism and eosinophilic colitis. Digestion. 2010;81:1279.

37- Tysk C, Bohr J, Nyhlin N, Wickbom A, Eriksson S. Diagnosis and management of microscopic colitis. World J Gastroenterol. 2008 ;14:7280-8.

38- Burgel N, Bojarski C, Mankertz J, Zeitz M, Fromm M, Schulzke JD. Mechanisms of diarrhea in collagenous colitis. Gastroenterology 2002;123:433-43.

39- Gunther U, Schuppan D, Bauer M, Matthes H, Stallmach A, Schmitt-Gräff A, et al. Fibrogenesis and fibrolysis in collagenous colitis. Patterns of procollagen types I and IV, matrix-metalloproteinase1 and -13, and TIMP-1 gene expression. Am J Pathol 1999; 155: 493-503. 
40- Bonderup OK, Hansen JB, Madsen P, Vestergaard V, Fallingborg J, Teglbjaerg PS. Budesonide treatment and expression of inducible nitric oxide synthase mRNA in colonic mucosa in collagenous colitis. Eur J Gastroenterol Hepatol 2006;18:1095-9.

41- Ozdil K, Sahin A, Calhan T, Kahraman R, Nigdelioglu A, Akyuz U, et al. The frequency of microscopic and focal active colitis in patients with irritable bowel syndrome. BMC Gastroenterol. 2011; 31;11:96.

42- Allende DS, Taylor SL, Bronner MP. Colonic perforation as a complication of collagenous colitis in a series of 12 patients. Am J Gastroenterol 2008;103:2598-604.

43- Baert F, Schmit A, D'Haens G, et al. Budesonide in collagenous colitis: a double-blind placebocontrolled trial with histologic follow-up. Gastroenterology. 2002;122:20-5.

44- Gremse DA, Boudreaux CW, Manci EA. Collagenous colitis in children. Gastroenterology. 1993 ;104:906-9.

45- Calabrese C, Fabbri A, Areni A, Zahlane D, Scialpi C, Di Febo G. Mesalazine with or without cholestyramine in the treatment of microscopic colitis: randomized controlled trial. J Gastroenterol Hepatol. 2007;22:809-14.

46- Wildt S, Munck LK, Vinter-Jensen L, Hanse BF, Nordgaard-Lassen I, Christensen S et al. Probiotic treatment of collagenous colitis: a randomized, double-blind, placebo-controlled trial with Lactobacillus acidophilus and Bifidobacterium animalis subsp. lactis. Inflamm Bowel Dis. 2006;12:395-401.

47- Pardi DS, Loftus EV Jr, Tremaine WJ, Sandborn WJ. Treatment of refractory microscopic colitis with azathioprine and 6-mercaptopurine. Gastroenterology. 2001;120:1483-4.

48- Esteve M, Mahadevan U, Sainz E, Rodriguez E, Salas A, Fernández-Bañares F. Efficacy of antiTNF therapies in refractory severe microscopic colitis. J Crohns Colitis. 2011;5:612-8.

49- Münch A, Ignatova S, Ström M. Adalimumab in budesonide and methotrexate refractory collagenous colitis. Scand J Gastroenterol. 2012;47:59-63.

50- Varghese L, Galandiuk S, Tremaine WJ, Burgart LJ. Lymphocytic colitis treated with proctocolectomy and ileal J-pouch-anal anastomosis: report of a case. Dis Colon Rectum. 2002;45:1236. 